\title{
ПРОБЛЕМЫ ПРИМЕНЕНИЯ СТАТЬИ 54.1 НАЛОГОВОГО КОДЕКСА РОССИЙСКОЙ ФЕДЕРАЦИИ ПРИ ПРОВЕДЕНИИ НАЛОГОВОГО КОНТРОЛЯ
}

\author{
Унисков Роман Олегович \\ Студент, \\ Самарский государственньий экономический университет \\ Калашникова Елена Борисовна \\ Кандидат исторических наук, доцент, \\ Самарский государственный экономический университет
}

\begin{abstract}
Аннотация. Статья посвящена практике применения соблюдения требований статьи 54.1 Налогового кодекса Российской Федерации по формированию доказательной базы должностными лицами налоговых органов при проведении камеральных и выездных налоговых проверок и принятию решений по проведенным камеральным и выездным налоговым проверкам.

Автор дает оценку соблюдения норм статьи 54.1 при формировании доказательной базы по проводимым мероприятиям должностными лицами, с целью соблюдения ими законодательства, нормативно-правовых актов при проведении камеральных и выездных налоговых проверок и вынесении решений по ним.
\end{abstract}

Ключевые слова: выездные налоговые проверки, статья, Налоговый кодекс РФ, обстоятельства, ФНС России, проблемы применения статьи, уточненная декларация по НДС, разрывы в цепочке.

\section{PROBLEMS OF APPLICATION OF ARTICLE 54.1 OF THE TAX CODE OF THE RUSSIAN FEDERATION DURING TAX CONTROL}

\author{
Uniskov Roman Olegovich \\ Student, \\ Samara State Economic University \\ Kalashnikova Elena Borisovna \\ Candidate of Historical Sciences, Associate Professor, \\ Samara State Economic University
}

\begin{abstract}
The article is devoted to the practice of applying compliance with the requirements of Article 54.1 of the Tax Code of the Russian Federation on the formation of an evidence base by tax officials when conducting desk and field tax audits and making decisions on the conducted desk and field tax audits.

The author gives an assessment of compliance with the norms of Article 54.1 in the formation of the evidence base on the activities carried out by officials, in order to comply with the legislation, regulatory legal acts when conducting desk and field tax audits and making decisions on them.
\end{abstract}

Key words: on-site tax audits, article, Tax Code of the Russian Federation, circumstances, Federal Tax Service of Russia, problems of application of the article, updated VAT declaration, gaps in the chain.

В СССР налоговой системы не существовало.

До начала «перестройки» контроль за исчислением и сбором налоговых платежей и сборов осуществлялся Министерством финансов СССР.

Министерством финансов СССР была построена система планирования финансовохозяйственной деятельности предприятий и организаций, при которой каждым предприятием и организацией составлялись промфинпланы, содержащие конечные результаты деятельности, и представлялись в финансовые отделы и вышестоящие организации на их утверждение. 
Финансовыми отделами (отделы КРУ) и вышестоящей организацией осуществлялся контроль за перечислением в бюджет свободного остатка прибыли, начислением и уплатой налога с оборота путем проведения ежегодных ревизий за выполнением спущенных производственных планов и предоставляемым государством финансирования.

В начале 90-х стала перестраиваться вся система государственного планирования и была создана налоговая система: был принят Закон Российской Федерации «Об основах налоговой системы» № 2118-1 от 21.12.1991г. Закон давал понятия налогов и сборов, формулировал основные принципы налогообложения и льготы при налогообложении. Заработала фискальная система. Принятые законы не давали точного определения погашения налогов. В этот период стали в основном применятся зачетная система и оплата векселями. Погашение налогов и сборов неденежными средствами привело к определенным трудностям.

Основными источниками доходной части бюджета были: подоходный налог, налог на прибыль, акцизы, налог на имущество, НДС, земельный налог, налог, связанный с разработкой и добычей ископаемых, налог на реализацию ГСМ, налог на пользователей автодорог, налог с владельцев транспортных средств, акцизы на автомобили, приобретаемые в личное пользование, налог на операции с ценными бумагами, дорожные фонды, доходы от продажи валюты, налог с продаж, налог на холостяков и малосемейных граждан.

Принятые в спешке законы не давали эффективности и содержали противоречия, что давало возможность уклонения от уплаты налогов. Многие предприятия не платили налоги. Все это требовало проведения налоговой реформы.

В 1998 году была принята часть первая Налогового кодекса Российской Федерации, а в 2002 году были приняты части главы второй Налогового кодекса Российской Федерации.

Контроль за деятельностью предприятий и организаций стали осуществлять налоговые органы путем проведения камеральных и выездных проверок.

Постановлением Пленума Высшего Арбитражного Суда Российской Федерации от 12 октября 2006 года № 53 была введена обязанность налоговых органов доказывать получение необоснованной налоговой выгоды налогоплательщиками: отсутствие должной осмотрительности при выборе контрагента, наличие взаимозависимости и аффилированности налогоплательщика с контрагентом и ее влияние на получение налоговой выгоды.

При проведении выездных налоговых проверок, в силу либо некомпетентности, либо превышения должностных полномочий, сотрудниками налоговых органов доначисление налогов по результатам проверок производилось без приведения доказательств о получении необоснованной налоговой выгоды налогоплательщиками.

В актах проверок производилась формальная ссылка на Постановление Пленума Высшего Арбитражного Суда Российской Федерации от 12 октября 2006 года № 53, что приводило к многочисленным судебным разбирательствам.

Доказательства налогового органа в части получения необоснованной налоговой выгоды сводились в основном к определению взаимосвязанности лиц, задействованных в процессе сделок, наличия у них одного юридического и IP-адреса.

Выводы о получении необоснованной налоговой выгоды делались по результатам выявленной взаимозависимости о согласованности налогоплательщика с взаимозависимыми лицами.

На основании взаимозависимости делался вывод об отсутствии реальности сделок.

Выводы должностных лиц, осуществляющих проверки, об отсутствии реальности сделок без приведения доказательств вызывали спорные вопросы с налогоплательщиками по их обоснованности и вели к судебным разбирательствам.

Введение в действие статьи 54.1 Налогового кодекса Российской Федерации планировалось с целью предотвращения незаконных действий налогоплательщиков по снижению налоговых обязательств. 
Действие данной статьи направлено на предотвращение злоупотреблений со стороны налогоплательщиков с учетом сложившейся судебной практики.

Однако на самом деле введение указанной статьи в действие создало проблемы не только для недобросовестных налогоплательщиков, но и для организаций, которые добросовестно платили налоги.

В статье 54.1 Налогового кодекса Российской Федерации, с учетом сложившейся судебной практики, более расширенно приведены признаки и действия налогоплательщиков по искажению хозяйственных операций, направленных на получение налоговой выгоды.

Действия налогоплательщика по искажению фактов хозяйственной жизни влекут к признанию нереальными (отраженными на бумаге) совершенных операций при проведении налоговых проверок. При проведении камеральных и выездных проверок налоговый орган должен доказать факты искажения хозяйственных операций, несоответствие делового документооборота обычным условиям его ведения.

При формировании доказательств по искажению хозяйственных операций, ведению формального документооборота, отсутствия реальности сделок, направленных на получение налоговой выгоды, налоговый орган должен учитывать, что недобросовестность контрагентов второго, третьего и последующих звеньев не должна учитываться. Данные условия регламентированы п. 5 ст. 82 НК РФ.

Данный факт также подтверждается судебной практикой.

В Определении Судебной коллегии по экономическим спорам Верховного Суда Российской Федерации от 14.05.2020 г. № 307-ЭС19-27597 указано, что налогоплательщик, не преследующий цель уклонения от уплаты налогов и действующий в рамках разумного ведения хозяйственного оборота, не знал и не мог знать о допущенных контрагентами нарушениях налогового законодательства и поэтому не мог их предотвратить.

При формировании доказательств налоговый орган должен учитывать положения п. 3 ст. 54.1 Налогового кодекса РФ, определяющие условия недобросовестности налогоплательщика, которые не могут быть использованы налоговым органом в качестве самостоятельных фактов доказательств получения налоговой выгоды, формального отражения хозяйственных операций.

Фактически при проведении выездных и камеральных проверок налоговыми органами применяются в основном пункты 1 и 2 статьи 54.1 Налогового кодекса РФ и игнорируется пункт 3 статьи 54.1 Налогового кодекса РФ при заключении выводов о злоупотреблениях налогоплательщиков.

В связи с введением в действие статьи 54.1 Налогового кодекса РФ, ФНС выпустила несколько писем, разъясняющих применение статьи 54.1 Налогового кодекса РФ при проведении камеральных и выездных проверок, при этом в письмах приводилась судебная практика только в пользу налоговых органов.

В письме 16.08.2017 N CA-4-7/16152@ ФНС указывает, что норма п.1 ст. 54.1 НК РФ определяет условия, которые препятствуют созданию схем уклонения от уплаты налогов. В письме указано, что налоговыми органами, осуществляющими проверки, должны быть исследованы все обстоятельства, подтверждающие (опровергающие) реальность сделки с контрагентом, и доначисление налогов возможно лишь при доказательстве налогового органа факта нереальности сделки.

Умышленные действия налогоплательщика, направленные на получение налоговой выгоды, должны быть исследованы налоговым органом.

В выводах налоговых органов, свидетельствующих об умышленных действиях налогоплательщика, должны быть приведены доказательства. К фактам умышленных действий, направленных на получение налоговой выгоды, могут относиться: подконтрольность и взаимозависимость налогоплательщика и контрагентов, факты наличия «транзитных» операций между взаимозависимыми лицами, согласованность действий с контрагенTOM. 
В случае доказанности умышленных действий, направленных на занижение налоговых обязательств, обязательства, возникшие в результате проведения нереальных сделок, корректируются полностью.

В письме ФНС России от 31.10.2017 № ЕД-4-9/22123@ «О рекомендациях по применению ст. 54.1 НК РФ» указывается, что в целях применения статьи 54.1 НК РФ налоговым органам следует доказать, что целью предпринимательской деятельности явилось получение налоговой экономии, сделка не исполнена заявленным контрагентом и налогоплательщик использовал формальный документооборот.

Следует также учесть, что статья 54.1 НК РФ не содержит расширения полномочий налоговых органов при сборе доказательной базы, принцип добросовестности налогоплательщика сохраняет силу.

При доказательствах умышленных действий налогоплательщиков следует приводить конкретные действия должностных лиц организации, свидетельствующие о намерениях нанесения вреда бюджету.

Фактически, при проведении проверок, налоговым органом в качестве доказательства умышленных действий приводятся факты подконтрольности и согласованности участников сделки, наличия формального документооборота, отражения в учете заведомо искаженных данных, получения налоговой экономии. Доказательства отсутствия деловой цели, а также получения суммы экономической выгоды, сопровождаемой расчетом, не приводятся, что не позволит однозначно утверждать о получении (отсутствии) экономической выгоды.

Если при проведении проверки будет установлено, что целью сделки было получение налоговой экономии, то налоговым органом должны быть приведены доказательства, что сделка не имеет экономического смысла. При этом должна быть опровергнута реальность сделки путем приведения доказательств исполнения сделки иным лицом.

В этом случае налоговые органы должны эффективно использовать пояснения лиц, имеющих отношение к сделке, проводить осмотры помещений, территорий, документов, технических средств, сопоставление объема поставляемых товаров размеру складских помещений (территорий); инвентаризацию имущества; анализ и воссоздание полного баланса предприятия (товарного баланса, складского учета и т.п.) и другое.

При сборе доказательств налоговый орган должен четко понимать целесообразность проведения каждого мероприятия налогового контроля.

Наличие формального документооборота может быть подтверждено обналичиванием денежных средств, расходованием средств на нужды учредителей, должностных лиц, использованием одних IP-адресов, обнаружением печатей и документации контрагента на территории (в помещении) проверяемого налогоплательщика и другие.

Несоблюдение налогоплательщиком требований пункта 2 статьи 54.1 может подтверждаться нетипичностью документооборота, несоответствием обычаю делового оборота поведения участников сделки, должностных лиц налогоплательщика при заключении, сопровождении, оформлении результатов сделок.

Фактически при проведении камеральных и выездных проверок налоговым органом приводятся доказательства согласованности и умышленных действий налогоплательщика, выразившиеся в использовании одних IP-адресов, одних телефонов, взаимозависимости. Данные факты приводятся также в подтверждение отсутствия реальности сделок в совокупности с приведенными доказательствами отсутствия у контрагента сотрудников, складских помещений, основных средств, транспортных средств, отсутствия платежей за аренду помещения, отсутствия по месту регистрации и другие.

Факты того, что налогоплательщиком перед заключением сделок контрагент был проверен на сайте ИФНС, затребовал документацию о его регистрации и постановке на учет в налоговых органах, налоговым органом не учитываются для подтверждения реальности сделок. 
При этом уже не имеет значения должная осмотрительность организации при выборе контрагента.

При проверках основной упор делается на отсутствие реальности сделок, а если реальность подтверждается, то налоговый орган ищет способ доказать, что сделка не исполнена лицом, с которым заключен договор, либо в актах проверки делаются формальные выводы, без подтверждения доказательствами, о нарушении налогоплательщиком ст. 54.1 Налогового Кодекса РФ.

В актах проверки имеются многочисленные ссылки на большое количество фактов и обстоятельств, которые не могут влиять на нарушения, и тем самым налоговый орган маскирует недоказанность собственных выводов.

В актах проверок приводятся доказательства отражения поступления товаров (работ, услуг) и дальнейшее списание стоимости приобретенных товаров на расходы. В то же время налоговым органом данная сделка относится к нереальной, делается вывод о формальном документообороте и умышленных действиях сотрудников, направленных на получение налоговой выгоды, без проведения расчета получения положительного или отрицательного результата от сделок.

При проведении проверок не исследуются факты дальнейшего движения приобретенных товаров, работ, услуг - использования их в хозяйственной деятельности налогоплательщика.

Добросовестный налогоплательщик, получив информацию о контрагенте и заключив с ним сделку, приобретает товар, который в дальнейшем реализуется. С реализации исчисляются налоги на прибыль и НДС. Конечным результатом является получение прибыли.

Однако данный факт «опускается» налоговым органом, поскольку он не в пользу налоговых органов, что впоследствии приводит к судебным разбирательствам.

Налоговым органом приводятся выводы о том, что сделка была заключена с «технической» организацией и ни о каких реальных сделках не может быть речи.

У налогоплательщика исключается стоимость приобретенных товаров из расходов без корректировки доходов от полученных сделок, исключаются вычеты по НДС.

Налоговый орган при проведении проверок к «техническим» организациям относит организации, имеющие следующие данные:

- отсутствие персонала, необходимого для выполнения работ;

- отсутствие основных средств, транспортных средств и складских помещений;

- движение денежных средств на расчетных счетах не подтверждает реальной деятельности организации по причине отсутствия платежей, связанных с хозяйственной деятельностью (аренда помещений, заработная плата, коммунальные услуги и другие);

- отсутствие организации по юридическому адресу;

- низкая налоговая нагрузка.

Такой формальный подход со стороны налоговых органов к выявлению обстоятельств получения налогоплательщиком налоговой экономии порождает многочисленные судебные разбирательства.

При рассмотрении судами дел, связанных с применением статьи 54.1, ее применение трактуется по-разному: либо в пользу налоговых органов, либо в пользу налогоплательщика.

Постановление АС Восточно-Сибирского округа от 22.07.2020 N Ф02-3123/2020 по делу N A58-9333/2019 - суд признал нереальность сделок и признал законным решение налогового органа.

Постановление АС Уральского округа от 02.07.2020 N Ф09-1413/20 по делу N A76$15817 / 2019$ - налоговый орган отказал в вычете по трем счетам-фактурам по причине того, что их выписали «технические компании» и контрагенты были включены в цепочку для увеличения стоимости товара. 
Постановление Седьмого арбитражного апелляционного суда от 20 января 2020 года по делу № А27-17275/2019 - отменено решение налогового органа в части исключения вычетов по НДС и расходов по налогу на прибыль.

Возможность проведения «налоговой реконструкции» - определение реальных налоговых обязательств при введении в действие статьи 54.1 ФНС России полностью отменено. Минфин России полностью поддержал ФНС (Письмо Минфина России от 13 декабря 2019 г. № 01-03-11/97904).

В то же время статья 89 Налогового кодекса обязывает налоговый орган при проведении выездных проверок определять действительные результаты деятельности налогоплательщика.

В Определении Судебной коллегии по экономическим спорам Верховного Суда Российской Федерации от 14.05.2020 № 307-ЭС19-27597 указано, что налогоплательщик, не преследовавший цель уклонения от налогов и действующий в рамках разумного поведения, не может быть лишен права на вычеты, поскольку не знал о допущенных контрагентом нарушениях законодательства.

Сложившаяся в последнее время судебная практика дает надежду налогоплательщикам на то, что при применении ст. 54.1 НК РФ при налоговых проверках, при исключении стоимости приобретенных товаров из расходов, будет корректироваться и полученный доход от сделок (будет применяться «налоговая реконструкция»).

Постановление Арбитражного суда Северо-Западного округа от 19 марта 2020 г. по делу № А56-50990/2019; Определение ВС РФ от 11 июня 2020 г. № 307-ЭС208927 ; Постановление Арбитражного суда Западно-Сибирского округа от 9 июля 2020 г. № Ф04-611/2020 по делу № А27-17275/2019 (Кузбассконсервмолоко);

Постановление Тринадцатого арбитражного апелляционного суда от 30 июля 2020 г. № 13АП-5916/2020, № 13АП-5914/2020, № 13АП-4985/2020 по делу № А6585058/2019 (Балтийская экспедиторская компания);

Постановление Арбитражного суда Западно-Сибирского округа от 23 октября 2020 г. по делу № А27-14675/2019 (Сибирская инжиниринговая торговая компания);

Постановление Тринадцатого арбитражного апелляционного суда от 28 октября 2020 г. № 13АП-21631/2020, 13АП-21931/2020 по делу № А56-13469/2020 (Балтийская группа) и т. д.

В то же время доля дел, которые отвергают «налоговую реконструкцию», очень много.

Постановление Арбитражного суда Московского округа от 10 ноября 2020 г. № Ф0517165/2020 по делу № А41-83291/19, Постановление Восьмого арбитражного апелляционного суда от 9 июня 2020 г. № 08АП-18337/2019 по делу № А7515855/2019 , Постановление Арбитражного суда Поволжского округа от 4 июня 2020 г. № Ф06-61054/2020 по делу № А55-26674/2019, Определение ВС РФ от 18 сентября 2020 г. № 306-ЭС20-11944 и другие.

Судами в указанных случаях подтверждаются выводы нижестоящих судов о том, что ст. 54.1 устанавливает повышенную ответственность.

Верховный суд подтвердил правомерность принятых решений в принятии и отказе «налоговой реконструкции» судебными инстанциями.

В то же время ФНС России доводит до нижестоящих органов только отрицательную судебную практику, как подтверждающую собственное мнение по неприменению «налоговой реконструкции».

Исходя из неопределенности применения ст. 54.1 НК РФ возникла необходимость дополнительных разъяснений по ее применению.

Разговоры о дополнительном выпуске письма начались около года назад, и на форуме представители ФНС подтвердили информацию, сообщив, что ведется подготовка проекта соответствующего документа. 
Что касается споров с участием «технических» организаций, то предусматривается два варианта: приводятся доказательства причастности налогоплательщика к формальному документообороту, встраивания в него «технических» организаций, и сбор доказательств о том, что налогоплательщик знал о «технических» организациях.

ФНС России письмом от 10.03.21г. № БВ-4-7/3060@ «О практике применения ст. 54.1 НК РФ» направлены нижестоящим налоговым органам рекомендации для доказывания выявленных нарушений законодательства при исчислении налогов налогоплательщиком, а также с целью обоснования выводов по проведенным контрольным мероприятиям при рассмотрении судебных споров.

В письме приведены примеры искажения данных налогоплательщиками с целью занижения налогов, подлежащих уплате в бюджет. Даны рекомендации налоговым органам по установлению и оценке умышленных действий налогоплательщиков, использующих формальный документооборот с участием «технических компаний».

В рекомендациях указано, что налоговым органом не применяется «налоговая реконструкция», поскольку налогоплательщик не представил данные о фактическом исполнителе: право на вычет НДС не представляется, расходы по проведенным сделкам не учитываются и расчетный способ определения налоговой обязанности, предусмотренный п.1 ст. 31 НК РФ, не применяется.

Поскольку судебная практика исходит из стандарта осмотрительности и добросовестности контрагента, то в письме ФНС от 10.03.21 г. №5В-4-7/3060@ даны указания по оценке обстоятельств, характеризующих выбор контрагента.

Если налогоплательщиком будет доказана его осмотрительность при выборе контрагента, то в его действиях не будет признано правонарушений. В таком случае он имеет право на предъявление НДС к вычету и учету расходов.

Для определения цели неправомерного уменьшения НДС налоговым органам следует определить, существенно ли отклоняются цены приобретения товаров от рыночных, а также определить деловую цель проведенных сделок, отсутствие дробления бизнеса.

Письмо ФНС от 10.03.21 г. № БВ-4-7/3060@, как и предыдущие письма, не содержит конкретных указаний по определению умышленных действий налогоплательщиков в части неправомерного уменьшения налоговой базы, связанных с искажением налогоплательщиком фактов хозяйственной жизни, что продолжит все более разгорающиеся споры по применению статьи 54.1 НК РФ.

В настоящее время в налоговой системе проводится реорганизация: проводится укрупнение районных ФНС, намечены мероприятия по введению систем контроля банковских счетов налогоплательщиков, физических лиц (АСК-3), усовершенствуется действующая система контроля АСК НДС - 2, увеличиваются случаи привлечения органов министерства внутренних дел к проведению контрольных мероприятий.

Введение данных систем в действие без внесения изменений в налоговое законодательство, регламентирующее исчисление налогов, возможно, приведет к многочисленным судебным разбирательствам.

Система АСК НДС - 2 позволяет контролировать цепочку налогоплательщиков, задействованных в вычетах по НДС, выявлять взаимосвязь между налогоплательщиками, постановку на налоговый учет, и прочее.

При введении в действие указанной программы не урегулирован вопрос по подаче уточненной декларации по НДС при изменении данных книг покупок и продаж, не влекущих изменения налога.

В статье 81 Налогового кодекса Российской Федерации предусмотрены случаи обязательной подачи уточненной декларации по НДС: сумма налога изменяется при внесении исправлений - возникает обязанность по подаче уточненной декларации, сумма налога не изменяется при внесении исправлений в декларацию по НДС - возникает право налогоплательщика подать (не подавать) уточненную декларацию. 
По этой причине могут возникнуть разрывы в цепочке, влекущие к запросам пояснений у налогоплательщиков и создание нервозной обстановки.

\section{Список источников и литературы}

1. Налоговый кодекс Российской Федерации (часть первая) от 31.07.1998 № 146-Ф3 (ред. от 20.04.2021) (с изм. и доп., вступ. в силу с 01.07.2021). - Текст : электронный // КонсультантПлюс : сайт. - 2021. - URL: http://www.consultant.ru (дата обращения: 22.04.2021).

2. О применении норм Федерального закона от 18.07.2017 № 163-Ф3 «О внесении изменений в часть Налогового кодекса Российской Федерации» : письмо ФНС России от 16.08.2017 № CA-4-7/16152@ - Текст : электронный // КонсультантПлюс : сайт. 2021. - URL: http://www.consultant.ru (дата обращения: 22.04.2021).

3. О рекомендациях по применению ст. 54.1 НК РФ : письмо ФНС России от 31.10.2017 № ЕД-4-9/22123@ - Текст : электронный // КонсультантПлюс : сайт. - 2021. - URL: http://www.consultant.ru (дата обращения: 22.04.2021). 